\title{
Arizona's botched execution of Joseph Wood violated the Eighth Amendment and highlighted the U.S. lethal-injection problem-dwindling drug supplies and too much secrecy
}

\author{
Last week saw the controversial execution in Arizona of Joseph Wood by lethal injection. Nancy \\ E. Millar argues that the procedure, which lasted for two hours, illustrates the major problems \\ with the way that executions are now carried out in the U.S. She writes that the growing \\ reluctance of pharmaceutical companies to provide the required drugs, in combination with the \\ secrecy laws enacted by states over them and the staff who carry them out, puts those to be \\ executed at risk of undergoing cruel and unusual punishment - a violation of the Eight \\ Amendment to the Constitution.
}

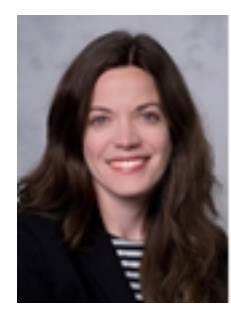

\begin{abstract}
"The Arizona Department of Corrections began the execution of Joseph Rudolph Wood III at 1:52 p.m. At 1:57 p.m[.] ADC reported that Mr. Wood was sedated, but at 2:02 he began to breathe. At 2:03 his mouth moved. Mr. Wood has continued to breathe since that time. He has been gasping and snorting for more than an hour. At 3:02 p.m. [], staff rechecked for sedation. He is still alive. This execution has violated Mr. Wood's Eighth Amendment right to be executed in the absence of cruel and unusual punishment."
\end{abstract}

So begins the emergency motion for stay of execution filed by Joseph Wood's attorneys during his execution by lethal injection last week. The fact that his attorneys had sufficient time to file such a motion during the procedure - which typically leads to death within ten minutes or so-demonstrates that Mr. Wood's execution was far from typical.

As the fourth botched U.S. execution of 2014, "the worst year in the history of lethal injection," Mr. Wood's execution by the state of Arizona demonstrates a critical problem in the current U.S. approach to execution and has the dubious distinction of being the longest and most unsettling execution by lethal injection in recent history.

The heart of the problem is that drug manufacturers and medical professionals do not want to be publicly involved in executions. The pharmaceutical company, Hospira, for example, chose to stop manufacturing sodium thiopental altogether after Italian authorities expressed concern about the drug, made in an Italian plant, being used in U.S. executions. Various drug companies have issued distribution controls prohibiting their drugs from being used for executions. The American Medical Association and other medical groups have stated that participation in executions violates medical ethics. So, in order to preserve the anonymity of companies and staff, states enact secrecy laws to protect them. This, in turn, means that prisoners cannot acquire key information about their impending executions and puts them at risk of botched procedures involving unsafe drugs, incompetent medical staff, or both.

A typical lethal injection might take 10 to 35 minutes and involves no movement or breathing during that time. One witness to Mr. Wood's execution, a reporter for The Arizona Republic, wrote that Mr. Wood took 660 gulps during the almost two-hour-long procedure. (A spokesperson for the Arizona attorney general's office disputed this account, telling The Washington Post that Mr. Wood was merely snoring.) Even conservative Senator John McCain (R-AZ) called the execution "torture" and said in an interview with Politico that "[t]he lethal injection needs to be an indeed lethal injection and not the bollocks-upped situation that just prevailed." 


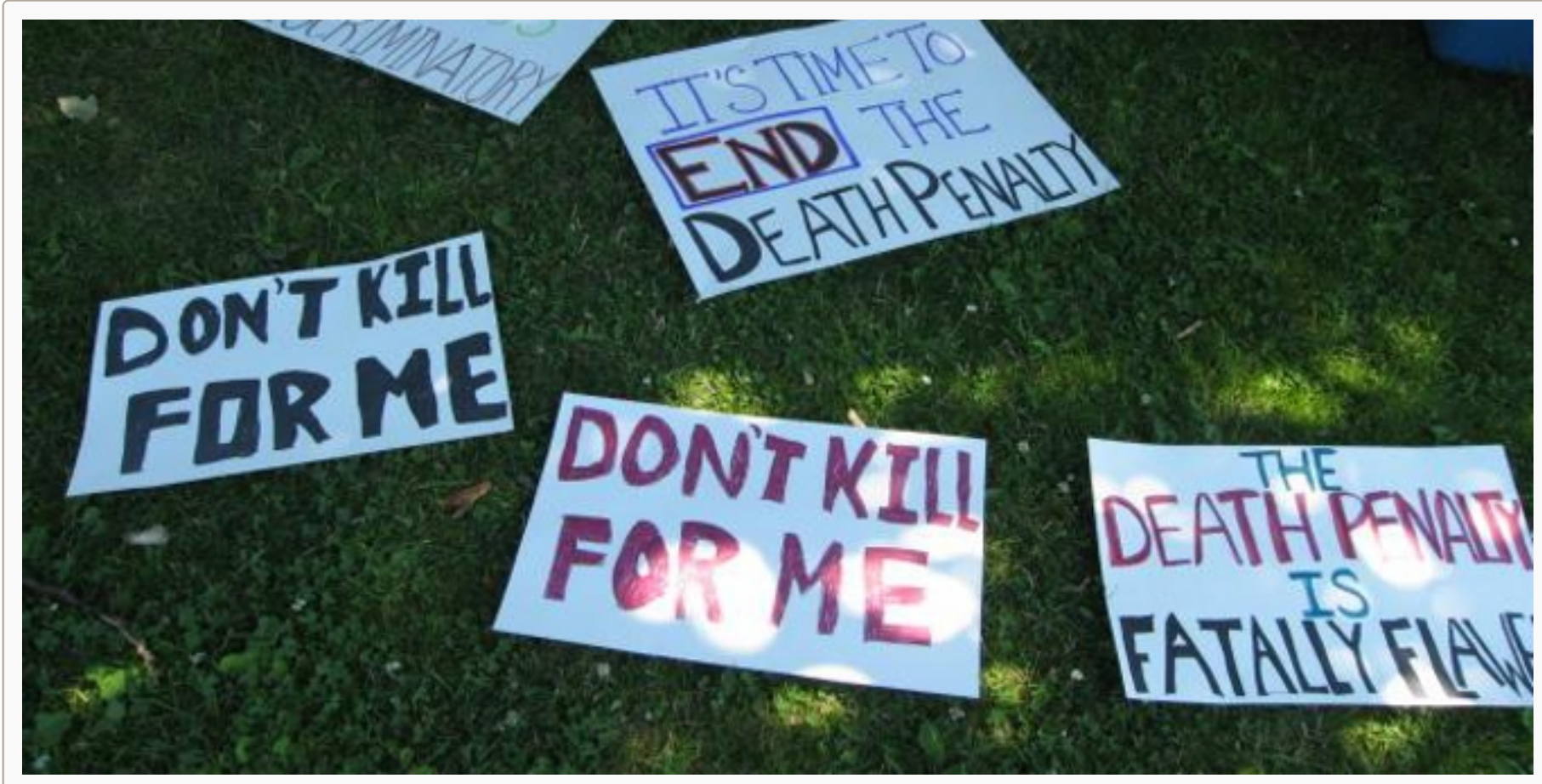

Credit: javacolleen (Flickr, CC-BY-NC-ND-2.0)

Last week's debacle, which quickly became international news, is not the first time Arizona's lethal injection protocols have sparked concern. Attorneys in the Office of the Federal Public Defender for the District of Arizona, which represented Mr. Wood, have been arguing for greater transparency and predictability in the process for years. In 2011, for example, on the eve of a scheduled execution, it was discovered that the Arizona Department of Corrections had bought the execution drug it planned to use from an unlawful source. In 2012, the state realized just two days before a scheduled execution that one of the drugs it planned to use had expired.

Mr. Wood's lawyers filed a motion for a preliminary injunction just a few weeks ago, arguing that Mr. Wood had a First Amendment right of access to non-confidential information relating to the execution-which is, of course, a government proceeding open to the public.

The Eighth Amendment to the U.S. Constitution prohibits the government from inflicting "cruel and unusual punishments." In a 2008 decision called Baze v. Rees, the Supreme Court considered it "settled" that capital punishment is constitutional and observed that "the Constitution does not demand the avoidance of all risk of pain in carrying out executions." In Baze, the Court held that the risk of improper administration of the initial drug in Kentucky's three-drug lethal-injection protocol did not render the punishment cruel and unusual.

As noted in Baze, the Court has never invalidated a state's chosen procedure for carrying out a death sentence on the grounds that it constituted infliction of cruel and unusual punishment. The Court in that opinion distinguished lethal injection and death by firing squad, both of which involved only a risk of pain, from punishments that deliberately aimed to inflict pain-noting "cases from England in which 'terror, pain, or disgrace were sometimes superadded' to the sentence, such as where the condemned was 'embowelled alive, beheaded, and quartered,' or instances of 'public dissection in murder, and burning alive."

The Baze Court explained that to prevail on an Eighth Amendment claim, a prisoner must demonstrate a '“substantial risk of serious harm,' an 'objectively intolerable risk of harm' that prevents prison officials from pleading that they were 'subjectively blameless for purposes of the Eighth Amendment." Dale Baich, one of Mr. Wood's attorneys, said in an interview that "[this] standard is so high it's almost impossible to meet."

Back in 2012, the Ninth Circuit found that "Arizona's actions [during executions came] perilously close to losing . . protection under Baze" and chastised the state for using inconsistent procedures during various executions, while "cling[ing] to its discretion, all the while urging us-during oral argument in the waning hours before execution-to trust that it will exercise its discretion in a constitutionally permissible manner." 
Last week, the state of Arizona deliberately proceeded to execute Mr. Wood using a two-drug combination that had been used only once before, in Ohio, where Dennis McGuire gasped several times during his 25-minute death on January 16. Despite almost two months of letters exchanged between Mr. Wood's counsel and the state, the attorney general failed to give Mr. Wood and his lawyers key information they sought in a motion for a preliminary injunction, including details about the drugs to be used and where they came from, the qualifications and certifications of the medical team, and an explanation of how the state developed its lethal-injection drug protocol.

Without this information, Mr. Wood could not properly investigate whether the state's planned execution using a controversial two-drug combination posted a "substantial risk of serious harm" and, thus, violated the Eighth Amendment. Without this information, he could not meet his heavy burden. So, without this information, Mr. Wood's execution went on as scheduled-and marked the midway point of 2014 with the longest and most troubling execution to date.

As a country, we are at a cross-road in our approach to the death penalty. Because drug manufacturers are placing distribution controls on their drugs to prevent their use in executions, states are turning to new, insufficiently tested drug protocols. Because medical professionals don't want the public to know they participate in executions, secrecy statutes prevent prisoners from evaluating whether medical staff members are properly qualified and competent. As a result, 2014 has emerged—in Ohio, Oklahoma, and here in Arizona-as a year of controversy, shame, and pain. One hopes that it is also a time for deep reflection.

Please read our comments policy before commenting.

Note: This article gives the views of the author, and not the position of USApp-American Politics and Policy, nor of the London School of Economics.

Shortened URL for this post: http://bit.ly/1ACx3wk

\section{About the author}

\section{Nancy E. Millar- Arizona Summit Law School}

Nancy E. Millar is an Assistant Professor of Law at Arizona Summit Law School in Phoenix. Her research interests include criminal law, international human rights, and women's rights. Follow her@LPprof.

- CC BY-NC-ND 3.02014 LSE USAPP

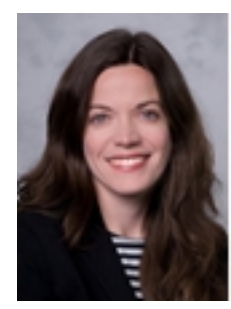

